\title{
When Should Pediatricians Become Concerned About Childhood Obesity?
}

\section{Teodoro Durá-Travé* and Fidel Gallinas-Victoriano}

Department of Pediatrics, Navarra Hospital Complex, Pamplona, Spain

\begin{abstract}
Objective: To analyze the chronological evolution of excess body weight (overweight and obesity) in order to raise public awareness within the different areas of intervention (family, school, business environment, health services) with the aim to take effective actions.
\end{abstract}

Material and methods: Weight, height and body mass index (BMI) of 604 healthy subjects $(307$ males and 297 females) have been recorded at birth and at the age of $1,2,3,4,6,8,10,12$ and 14 years. The excess body weight has been calculated according to national references.

Results: Prevalence of excess body weight at age 14 years was significantly higher $(p<0.05)$ in males $(29 \%)$ than in females $(12.8 \%)$. BMI $\left(\mathrm{kg} / \mathrm{m}^{2}\right)$ was significantly higher $(p<0.05)$ for both sexes in every period of age, except for birth and age 1 year, in those patients with excess body weight at age 14 with respect to patients with normal nutritional status of the same age. Those groups with excess body weight at age 14 showed BMI (Z-score) reaching overweight or obesity levels at age 4, and progressively increasing.

Conclusions: Excess body weight would start at early stages in life, when dietary habits of the children depend almost exclusively on family habits, and would be aggravated during school attendance. Finally, a disproportionate weight increase occurs in adolescence probably related to unhealthy dietary habits and lifestyle.

Keywords: Adolescents; Body mass index; Children; Obesity; Prevalence; Over weight

\section{Introduction}

Prevalence of childhood overweight and obesity has gradually increased in industrialized countries and is currently the leading nutrition disorder in our society [1-4]. Additionally, it should be considered that overweight/obesity in childhood, especially in school age, represent a high risk situation for overweight/obesity in adolescence [5-9]. The majority of obese adolescents will stay overweight in adulthood, with an additional risk of higher levels of morbidity and mortality [10-12].

The World Health Organization (WHO) considers obesity a major public health problem [13], given its labor, social, economic and sanitary impact. Within this context, a Spanish strategy for nutrition, physical activity and prevention of obesity (Estrategia para la Nutrición, Actividad Física y prevención de la Obesidad -NAOS-) [14], was designed in our country in order to support initiatives that contribute to achieve the necessary social change required to reverse the trend towards obesity. This strategic plan gives priority to the prevention of obesity in childhood/adolescence; in addition, it suggests the creation of an Obesity Observatory for the evaluation and monitoring of concrete steps to be adopted in the different areas of assistance (family, school, corporate and sanitary environment). Our community does not have a program for prevention of childhood obesity including specialized care as a counselor in the prevention and treatment of this disease. Therefore, this situation gives us the possibility of studying the "natural evolution" of excess body weight.

The objective of this study is to analyze the chronological evolution of excess body weight in our environment, and, in this way, to raise awareness in the different areas of intervention referred by the NAOS strategy to assume appropriate measures in each moment.

\section{Material and Methods}

An observational, longitudinal study achieved in an infant population (Caucasian healthy individuals, and the children of Caucasian parents from Spanish origin), whose methodology has been explained in detail in previous issues $[8,15]$, has permitted to obtain 604 healthy individuals aged 14 years (307 males and 297 females). These patients were attended according to the Healthcare Screening Program for pediatric population of the Community of Navarre [16] in 2007. Their anthropometric data (weight and height) were registered in their respective medical records. In the same way, the registration of the anthropometric data (weight and height) for each individual corresponding to birth and ages $1,2,3,4,6,8,10$ and 12 years was retrospectively obtained.

Body mass index (BMI) has been calculated using the following formula: weight $(\mathrm{kg}) /$ height $^{2}(\mathrm{~m})$. The $\mathrm{Z}$-score values for BMI were determined using the SEINAPTRACKER program (Medicalsoft Intercath, S.L. University of Barcelona, 2007-2008), being the charts and growing curves from Longas et al. [17] the reference patterns. BMI (Z-score) values of $+1.0\left(85^{\text {th }}\right.$ percentile $)$ and $+2.0\left(97^{\text {th }}\right.$ percentile $)$ were established as cut points in order to define overweight and obesity. In addition, the prevalence of excess body weight (overweight and obesity) at age 14 has been defined by the international references from Cole et al. [18], which set BMI cut points $\left(\mathrm{kg} / \mathrm{m}^{2}\right)$ to define overweight and obesity by extrapolation of adult values proposed by the WHO ( 25 and $30 \mathrm{~kg} / \mathrm{m}^{2}$ respectively). Patients were placed in three different groups: standard group (normal nutrition at age 14), overweight group (overweight at age 14) and obesity group (obesity at age 14).

Results are expressed as percentages (\%) and means (M) with corresponding standard deviations (SD). Statistical analysis (descriptive

*Corresponding author: Durá-Travé T, Department of Pediatrics, Avenue Irunlarrea, 4, 31008 Pamplona, Spain, Tel: +34 848 422563; Fax: +34 8484299 24; E-mail: tduratra@cfnavarra.es

Received May 13, 2013; Accepted June 05, 2013; Published June 07, 2013

Citation: Durá-Travé T, Gallinas-Victoriano F (2013) When Should Pediatricians Become Concerned About Childhood Obesity? J Nutr Disorders Ther 3: 124 doi:10.4172/2161-0509.1000124

Copyright: (C) 2013 Durá-Travé T, et al. This is an open-access article distributed under the terms of the Creative Commons Attribution License, which permits unrestricted use, distribution, and reproduction in any medium, provided the original author and source are credited. 
statistics, Student's t-Test, ANOVA, Chi-square Test) was performed using the Statistical Packages for the Social Sciences (SPSS) program, version 20.0 (Chicago, Illinois, USA). Statistical significance level was reached when $p$ value was lower than 0.05 .

\section{Results}

Table 1 shows and compares the prevalence of excess body weight (overweight and obesity) at age 14 in both sexes according to the reference patterns. There were not any statistically significant differences in the prevalence of overweight/obesity regardless of the references we applied. The prevalence of excess body weight (overweight/obesity) was significantly higher $(\mathrm{p}<0.05)$ in males in relation to females. Nevertheless, the percentage of patients with overweight was significantly higher than those with obesity in both sexes when applying the international references.

Table 2 displays and compares the mean values of weight $(\mathrm{kg})$, height $(\mathrm{cm})$ and BMI $\left(\mathrm{kg} / \mathrm{m}^{2}\right)$ that correspond to the different ages considered in the group of males who maintain normal nutrition at age 14 (standard group, $\mathrm{n}=218$ ) or have excess weight (overweight, $\mathrm{n}=55$ and obesity groups, $\mathrm{n}=34$ ). Mean values of weight were significantly higher $(\mathrm{p}<0.05)$ in every age in the groups with excess weight (overweight and obesity groups) with respect to the standard group, except for birth and age 1 year. There were not any statistically significant differences among mean values of height in the different groups at any age. Regarding BMI, the calculated mean values were significantly higher $(\mathrm{p}<0.05)$ in every age within the groups with excess body weight (overweight and obesity groups) with respect to the standard group, except for birth and age 1 .

Table 3 shows and analyzes mean values for weight $(\mathrm{kg})$, height $(\mathrm{cm})$ and BMI $\left(\mathrm{kg} / \mathrm{m}^{2}\right)$ corresponding to every age in females who show normal nutrition status at age 14 (standard group, $\mathrm{n}=259$ ) or have excess body weight (overweight, $\mathrm{n}=20$ and obesity groups, $\mathrm{n}=18$ ). Mean values of weight were significantly higher $(\mathrm{p}<0.05)$ at every age within the groups with excess body weight (overweight and obesity) with regard to the standard group, but for birth and age 1 year. There were not any significant differences regarding mean values of height at any age among the normal and overweight groups; however, mean values of height were significantly higher $(\mathrm{p}<0.05)$ at $2,3,4,6,8$ and

\begin{tabular}{|l|c|c|c|}
\hline \multirow{2}{*}{} & \multicolumn{2}{|c|}{ Ferrández et al. [17] } & \multicolumn{2}{c|}{ Cole et al. [18] } \\
\cline { 2 - 4 } & $\begin{array}{c}\text { Males } \\
\mathbf{n}(\%)\end{array}$ & $\begin{array}{c}\text { Females } \\
\mathbf{n}(\%)\end{array}$ & $\begin{array}{c}\text { Males } \\
\mathbf{n}(\%)\end{array}$ \\
\hline Overweight & $55(17,9 \%)$ & $20(6,7 \%)$ & $76(24,7 \%)$ \\
Obesity & $34(11,1 \%)$ & $18(6,1 \%)$ & $19(6,2 \%)$ \\
\hline Total & $89(29,0 \%)$ & $38(12,8 \%)$ & $11(3,7 \%)$ \\
\hline
\end{tabular}

Table 1: Prevalence of excess body weight (overweight and obesity) at age 14 according to national and International references.

\begin{tabular}{|c|c|c|c|}
\hline \multicolumn{4}{|c|}{ Weight (kg) } \\
\hline Age (years) & Standard group M (SD) & Overweight group M (SD) & Obesity group $M(D E)$ \\
\hline $\begin{array}{c}0 \\
1 \\
2 \\
3 \\
4 \\
6 \\
8 \\
10 \\
12 \\
14\end{array}$ & $\begin{array}{c}3.32(0.47) \\
10.14(0.95) \\
12.84(1.10) \\
15.12(1.34) \\
17.42(1.89) \\
21.82(2.82) \\
27.96(4.15) \\
34.84(5.38) \\
42.66(6.56) \\
54.35(8.16)\end{array}$ & $\begin{array}{c}3.39(0.44) \\
10.28(0.81) \\
13.31(1.27)^{\star} \\
15.85(1.81)^{\star} \\
18.31(2.28)^{\star} \\
24.31(3.44)^{*} \\
31.41(4.01)^{\star} \\
40.91(4.68)^{\star} \\
50.91(8.27)^{\star} \\
65.12(8.30)^{\star}\end{array}$ & $\begin{array}{c}3.32(0.42) \\
10.66(1.09) \\
13.33(1.56)^{\star} \\
16.35(1.96)^{\star} \\
19.86(2.23)^{\star} \\
26.82(4.44)^{\star} \\
37.14(6.06)^{\star} \\
47.92(7.26)^{\star} \\
63.81(12.3)^{\star} \\
81.47(126)^{*}\end{array}$ \\
\hline \multicolumn{4}{|c|}{ Height (cm) } \\
\hline Age (years) & Standard group M (SD) & Overweight group M (SD) & Obesity group M (SD) \\
\hline $\begin{array}{c}0 \\
1 \\
2 \\
3 \\
4 \\
6 \\
8 \\
10 \\
12 \\
14\end{array}$ & $\begin{array}{c}50.52(2.20) \\
76.46(2.66) \\
88.78(2.89) \\
97.17(2.88) \\
104.23(3.86) \\
117.17(4.60) \\
129.47(5.29) \\
140.19(5.80) \\
151.34(7.49) \\
165.89(8.19)\end{array}$ & $\begin{array}{c}50.63(2.02) \\
76.56(1.93) \\
88.71(3.06) \\
97.28(2.81) \\
104.39(3.91) \\
117.98(4.24) \\
129.29(4.80) \\
140.63(5.30) \\
151.19(7.78) \\
164.47(8.33)\end{array}$ & $\begin{array}{c}49.98(2.26) \\
76.80(2.53) \\
88.26(3.02) \\
97.15(3.45) \\
104.76(4.11) \\
118.58(4.53) \\
130.57(5.21) \\
142.02(6.61) \\
154.53(7.30) \\
165.71(7.17)\end{array}$ \\
\hline \multicolumn{4}{|c|}{ BMI $\left(\mathrm{kg} / \mathrm{m}^{2}\right)$} \\
\hline Age (years) & Standard group M (SD) & Overweight group M (SD) & Obesity group M (SD) \\
\hline $\begin{array}{c}0 \\
1 \\
2 \\
3 \\
4 \\
6 \\
8 \\
10 \\
12 \\
14\end{array}$ & $\begin{array}{l}12.98(1.34) \\
17.35(1.21) \\
16.29(0.99) \\
16.07(1.35) \\
15.94(1.08) \\
15.92(1.32) \\
16.62(1.76) \\
17.68(1.99) \\
18.55(1.99) \\
19.67(1.83)\end{array}$ & $\begin{array}{c}13.22(1.32) \\
17.48(1.25) \\
16.80(1.26)^{\star} \\
16.72(1.45)^{\star} \\
16.76(1.39)^{\star} \\
17.42(1.94)^{\star} \\
18.67(1.78)^{\star} \\
20.63(1.49)^{\star} \\
21.90(2.48)^{\star} \\
23.80(2.13)^{\star}\end{array}$ & $\begin{array}{c}12.92(1.94) \\
18.02(1.49) \\
17.06(1.23)^{\star} \\
17.28(1.47)^{\star} \\
18.06(1.27)^{\star} \\
18.98(2.26)^{\star} \\
21.66(2.40)^{\star} \\
23.68(2.56)^{\star} \\
26.57(3.60)^{\star} \\
29.05(4.74)^{\star}\end{array}$ \\
\hline
\end{tabular}

$\left(^{*}\right) p<0.05$ with respect to standard group

Table 2: Mean values for weight, height and BMI in males. 


\begin{tabular}{|c|c|c|c|}
\hline \multicolumn{4}{|c|}{ Weight (kg) } \\
\hline Age (years) & Standard group M (SD) & Overweight group $M$ (SD) & Obesity group M (SD) \\
\hline $\begin{array}{c}0 \\
1 \\
2 \\
3 \\
4 \\
6 \\
8 \\
10 \\
12 \\
14\end{array}$ & $\begin{array}{c}3.17(0.40) \\
9.73(1.26) \\
12.28(1.33) \\
14.60(1.56) \\
16.95(2.18) \\
21.70(3.03) \\
27.99(4.18) \\
35.11(6.11) \\
44.74(7.47) \\
51.74(6.67)\end{array}$ & $\begin{array}{c}3.17(0.38) \\
9.92(1.28) \\
13.02(1.51)^{*} \\
16.15(2.05)^{*} \\
18.16(2.56)^{*} \\
24.52(3.51)^{*} \\
32.71(4.96)^{*} \\
42.48(6.18)^{*} \\
54.34(10.1)^{*} \\
64.51(6.61)^{*}\end{array}$ & $\begin{array}{c}3.32(0.52) \\
10.24(1.08) \\
14.60(2.31)^{*} \\
18.65(3.35)^{*} \\
21.62(4.48)^{*} \\
28.95(4.80)^{*} \\
41.50(5.94)^{*} \\
51.68(6.24)^{*} \\
65.50(5.54)^{*} \\
77.12(8.45)^{*}\end{array}$ \\
\hline \multicolumn{4}{|c|}{ Height (cm) } \\
\hline Age (years) & Standard group M (SD) & Overweight group $M(S D)$ & Obesity group $M(S D)$ \\
\hline $\begin{array}{c}0 \\
1 \\
2 \\
3 \\
4 \\
6 \\
8 \\
10 \\
12 \\
14\end{array}$ & $\begin{array}{c}49.64(2.07) \\
75.26(2.66) \\
87.21(3.00) \\
96.59(3.25) \\
103.20(3.87) \\
116.66(4.40) \\
129.70(5.09) \\
140.16(6.13) \\
153.61(7.05) \\
160.88(5.94)\end{array}$ & $\begin{array}{c}50.10(2.06) \\
74.56(2.61) \\
87.53(3.26) \\
97.88(4.08) \\
103.48(4.63) \\
118.18(5.46) \\
131.28(5.55) \\
142.67(7.08) \\
155.93(8.23) \\
161.45(6.37)\end{array}$ & $\begin{array}{c}49.29(2.31) \\
76.10(2.68) \\
89.68(4.06)^{\star} \\
98.97(3.43)^{\star} \\
106.42(4.68)^{\star} \\
119.12(4.91)^{*} \\
134.40(4.53)^{*} \\
144.73(5.69)^{*} \\
155.00(5.72) \\
162.77(4.97)\end{array}$ \\
\hline \multicolumn{4}{|c|}{ BMI $\left(\mathbf{k g} / \mathbf{m}^{2}\right)$} \\
\hline Age (years) & Standard group M (SD) & Overweight group $M$ (SD) & Obesity group M (SD) \\
\hline $\begin{array}{c}0 \\
1 \\
2 \\
3 \\
4 \\
6 \\
8 \\
10 \\
12 \\
14\end{array}$ & $\begin{array}{l}12.84(1.12) \\
17.10(1.40) \\
16.14(1.36) \\
15.95(1.28) \\
15.87(1.49) \\
15.89(1.61) \\
16.93(2.08) \\
17.69(2.12) \\
18.71(2.24) \\
19.95(1.99)\end{array}$ & $\begin{array}{c}12.64(1.11) \\
17.64(1.16) \\
17.01(1.40)^{*} \\
16.83(1.66)^{*} \\
16.89(1.39)^{\star} \\
17.47(1.45)^{\star} \\
18.92(2.12)^{*} \\
20.79(1.95)^{*} \\
22.21(2.91)^{*} \\
24.22(3.05)^{*}\end{array}$ & $\begin{array}{c}13.60(1.49) \\
17.66(1.28) \\
18.04(1.81)^{*} \\
18.89(2.25)^{*} \\
18.92(2.71)^{*} \\
20.30(2.26)^{*} \\
22.89(2.26)^{*} \\
23.91(2.90)^{*} \\
27.65(1.27)^{*} \\
28.49(3.64)^{*}\end{array}$ \\
\hline
\end{tabular}

$\left({ }^{*}\right) p<0.05$ with respect to standard group

Table 3: Mean values for weight, height and BMI in females.

10 years of age within the obesity group with respect to the standard group. With respect to BMI, mean values were significantly higher $(\mathrm{p}<0.05)$ within the groups with excess body weight (overweight and obesity groups) compared to the standard group in every age, except for birth and age 1 .

Figure 1 shows and compares mean values for BMI (Z-score) corresponding to the different ages of the groups whose individuals showed normal nutrition at age 14 (standard group) or have excess body weight (overweight and obesity group). Even when mean values for BMI $(Z$-score) were significantly higher $(\mathrm{p}<0.05)$ beyond 2 years of age within the groups with excess weight (overweight and obesity) with respect to the standard group, it was after 4 years of age when the values reached the range of overweight and obesity, respectively, and it would remain so until 14 years of age.

\section{Discussion}

Excess body weight (overweight and obesity) is a multifactorial disorder whose pathogenesis includes genetic, metabolic, psychosocial and environmental factors. Nevertheless, this fast increase in its prevalence seems to be related to environmental factors, such as lack of healthy nutrition habits and sedentary lifestyle (a decrease in physical activity in children and adolescents conditioned, to a great extent, by television and/or new technologies). It is precisely the NAOS [14] strategy which emerges as a response to that ascending tendency of overweight and obesity in our society, pretending to promote a series of programs addressed to infant-juvenile population, whose dietary habits and lifestyle have not yet become established; they are, therefore, improvable through education programs.

There are not uniform reference values, at present day, which allow for a precise diagnosis of excess body weight. Therefore, the epidemiological data that have been published attending this matter are quite variable and make international, and even national comparisons, fairly complicated $[4,19,20]$. However, body mass index is considered an acceptable anthropometric parameter to define excess body weight [21-24]. In this way, the application of international reference standards suggested by Cole el al. [18] is considered appropriate, although whenever there are local reference charts, their use is preferential. In this case, international as well as qualified national criteria have been applied to calculate the prevalence of excess body weight at age 14 . The results we have obtained suggest, on one side, that one out of five adolescents present overweight/obesity at the end of the pediatric age, and it is basically similar regardless of the reference values applied; on the other side, they confirm that overweight and obesity affect males at a higher rate than women. Nevertheless, as it happened in this case, whenever the international standards from Cole et al. have been applied, the percentage of obesity show very low levels, whereas overweight reaches relatively high levels. This means, it suggests that these reference values tend to underestimate obesity and overestimate overweight $[23,25]$, and this would justify the use of updated national references in clinical practice, as we have done in this study.

The comparison of the rates of prevalence of excess body weight registered at age 14 with the results of different national and 


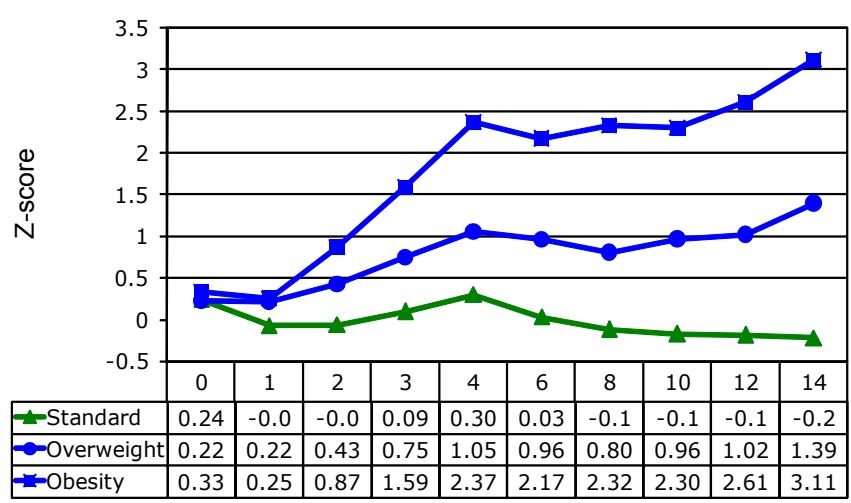

Figure 1: Evolution of mean values for BMI (Z-score) at different ages in the standard group and overweight and obesity groups.

international studies that have been published applying the standards from Cole et al. reveals that the rate of prevalence of excess weight in our environment (one out of five adolescents at age 14) is basically similar to that of the rest of Spanish regions $[23,26,27]$ and industrialized countries [4,25,28-30]. However, we should remark how -in both sexes- adolescents who had excess body weight at age 14 years showed body mass index significantly higher at age 2 with respect to those who presented with normal nutrition at age 14; furthermore, these differences gradually increased throughout growing-up. It seems that excess body weight would be a nosological entity that begins at early stages in life in which diet depends almost exclusively on dietary habits and/or behavior in the familiar environment. It would later deteriorate at the time of school attendance, probably due to the acquisition of a certain degree of autonomy in feeding, since they usually do some of the daily intake out of their houses, in school lunch room or without family supervision. Finally, a disproportionate weight increase would take place during adolescence, especially in males, probably in relation to unhealthy acquired dietary habits and lifestyle.

The early onset of weight increase and its persistence throughout childhood/adolescence, and, consequently, the increase of risk of overweight/obesity in adult life, make the development of active policies in different areas of intervention mandatory: community and family, school, business and sanitary environments. On one side, families should get basic nutrition knowledge (institutional advertising, informational resources, interactive applications, etc.) in order to create healthy eating habits and/or lifestyles in children; at the same time, children would be given the education to develop them within school environment. Mass catering, and concretely school meals, is in an expansion stage as a consequence of new ways of social and familiar organization, and more and more every day, families delegate some of the meals of their children in these services and/or catering companies. School dining room is one of the most interesting instruments in school environment, since it could help strengthen acquired knowledge and healthy eating habits. This means, it would serve as a transmitter of nutrition education since the theoretical dietary proposals for daily life in adolescents would be adapted through it, so contributing to the affective adhesion to healthy dietary habits. We should remark that the deterioration of the dietary model is, to a great extent, conditioned by a high availability of food, and specifically, by a permissive accessibility to processed food (industrial pastries, soft drinks, sweets, chocolate, industrial fruit juices, etc.). Processed food consumption should be casual and means a higher calorie intake, as well as total fat and saturated fat, refined sugar and cholesterol. Considering school and familiar environment as the educational areas with the greatest influence for the acquisition of healthy eating habits and lifestyles, the attitude to be adopted by the school centers regarding nutrition aspects should be inherently exemplary in order to accomplish its educational purposes. Consequently, it would contribute to avoid infant-juvenile overweight and obesity. For instance, the limitation and/or modification of selling of high calorie food in school centers (food and soft drinks vending machines) would be appropriate as a coherent pedagogic measure facing a health problem that is due to a lack of individual, familiar and social education. With regard to business environment, food and beverage industry should commit in the development and commercial distribution of more healthy products by means of modifying the composition of food (low salt, saturated fat and refined sugar) and/ or issuing nutrition information (food advertising, labeling, internet portals, etc.). Hospitality and restaurant services should offer varied and nutrition-balanced feeding which allowed the consumer to choose healthy options. Finally, with respect to sanitary environment, primary health care teams, and more specifically pediatricians, should include a series of preventive measures to be applied within the preventive and health promotion programs in the first years of life, together with weight and height periodic control. Regular physical activity appropriate to every age should also be promoted, as well as the reinforcement of a series of general standards of behavior, such as respecting meal schedule, avoiding sedentary lifestyle and increase quotidian activity, reducing time for TV and/or new technologies, etc.

In order to achieve its goal (the promotion of healthy feeding and physical activity), the NAOS strategy proposed the creation of an Observatory of Obesity to assure a methodological homogeneity in the evaluation and monitoring of the different initiatives they promote to get its main objectives. In this sense, the lack of a program for the prevention of child obesity in our community (which would include specialized attention with the aim to be the essential structure of the NAOS strategy); makes the patients with excess body weight depend on primary care pediatrician in our environment. Even when they do play an essential role in the early detection of overweight, they lack the necessary perspective that a specialized consultation has to interfere with the "natural evolution" of overweight, since it has more complete evidence-based information on epidemiological, clinical and evolution factors.

\section{References}

1. Ogden CL, Carroll MD, Kit BK, Flegal KM (2012) Prevalence of obesity and trends in body mass index among US children and adolescents, 1999-2010. JAMA 307: 483-490.

2. Tzotzas T, Krassas GE (2004) Prevalence and trends of obesity in children and adults of South Europe. Pediatr Endocrinol Rev 1 Suppl 3: 448-454

3. Schober E, Rami B, Kirchengast S, Waldhör T, Sefranek R (2007) Recent trend in overweight and obesity in male adolescents in Austria: a population-based study. Eur J Pediatr 166: 709-714.

4. Livingstone B. Epidemiology of childhood obesity in Europe. Eur J Pediatr.2000 159(1 Suppl):14-34.

5. Durá-Travé T, Hualde-Olascoaga J, Garralda-Torres I; Grupo Colaborador de Navarra (2012) [Overweight among children in Navarra (Spain) and its impact on adolescence]. Med Clin (Barc) 138: 52-56.

6. Reilly JJ, Armstrong J, Dorosty AR, Emmett PM, Ness A, et al. (2005) Early life risk factors for obesity in childhood: cohort study. BMJ 330: 1357

7. Johannsson E, Arngrimsson SA, Thorsdottir I, Sveinsson T (2006) Tracking of overweight from early childhood to adolescence in cohorts born 1988 and 1994 overweight in a high birth weight population. Int J Obes (Lond) 30: 1265-1271.

8. Nader PR, O'Brien M, Houts R, Bradley R, Belsky J,et al. (2006) Nationa 
Institute of Child Health and Human Development Early Child Care Research Network. Identifying risk for obesity in early childhood. Pediatrics 118: e594601

9. Wright CM, Emmett PM, Ness AR, Reilly JJ, Sherriff A (2010) Tracking of obesity and body fatness through mid-childhood. Arch Dis Child 95: 612-617.

10. Freedman DS, Khan LK, Serdula MK, Dietz WH, Srinivasan SR, et al. (2005) The relation of childhood BMI to adult adiposity: the Bogalusa Heart Study. Pediatrics 115: 22-27.

11. Biro FM, Wien M (2010) Childhood obesity and adult morbidities. Am J Clin Nutr 91: 1499S-1505S.

12. Field AE, Cook NR, Gillman MW (2005) Weight status in childhood as a predictor of becoming overweight or hypertensive in early adulthood. Obes Res 13: $163-169$

13. http://www.euro.who.int/document/e89858.pdf

14. http://www.naos.aesan.msssi.gob.es/naos/estrategia/que_es/

15. Durá Travé T, Garralda Torres I, Hualde Olascoaga J; Grupo Colaborador de Navarra (2009) Longitudinal study of child growth in Navarre (1993-2007). An Pediatr (Barc) 70: 526-533.

16. Atención a la población infantil y adolescente en Atención Primaria (2000) Guía de actuación, Departamento de Salud, Gobierno de Navarra, Pamplona.

17. Longas AF, Baguer L, Labarta JI, Labena C, Mayayo E, et al. (2005) Longitudina study of normal spanish children from birth to adulthood anthropometric, puberty, radiological and intellectual data. Pediatr Endocrinol Rev 2: 425.

18. Cole TJ, Bellizzi MC, Flegal KM, Dietz WH (2000) Establishing a standard definition for child overweight and obesity worldwide: international survey. BMJ 320: $1240-1243$

19. Serra Majem L, Ribas Barba L, Aranceta Bartrina J, Pérez Rodrigo C, Saavedra Santana P, et al. (2003) [Childhood and adolescent obesity in Spain. Results of the enKid study (1998-2000)]. Med Clin (Barc) 121: 725-732.

20. Lobstein T, Frelut ML (2003) Prevalence of overweight among children in Europe. Obes Rev 4: 195-200.
21. Dietz WH, Bellizzi MC (1999) Introduction: the use of body mass index to assess obesity in children. Am J Clin Nutr 70: 123S-5S

22. Reilly JJ, Dorosty AR, Emmett PM; Avon Longitudinal Study of Pregnancy and Childhood Study Team (2000) Identification of the obese child: adequacy of the body mass index for clinical practice and epidemiology. Int J Obes Relat Metab Disord 24: 1623-1627.

23. Marrodán Serrano MD, Mesa Santurino MS, Alba Díaz JA, Ambrosio Soblechero B, Barrio Caballero PA, et al. (2006) Obesity screening: updated criteria and their clinical and populational validity. An Pediatr (Barc) 65: 5-14.

24. Calañas-Continente A, José Arrizabalaga J, Caixàs A, Cordido F; Grupo de Trabajo sobre Obesidad de la Sociedad Española de Endocrinología y Nutrición (2010) Diagnostic and therapeutic recommendations for overweight and obesity during adolescence. Grupo de Trabajo sobre Obesidad de la Sociedad Española de Endocrinología y Nutrición. Med Clin (Barc) 135: 265 273.

25. Zimmermann MB, Gübeli C, Püntener C, Molinari L (2004) Detection of overweight and obesity in a national sample of 6-12-y-old Swiss children: accuracy and validity of reference values for body mass index from the US Centers for Disease Control and Prevention and the International Obesity Task Force. Am J Clin Nutr 79: 838-843.

26. Larrañaga N, Amiano P, Arrizabalaga JJ, Bidaurrazaga J, Gorostiza E (2007) Prevalence of obesity in 4-18-year-old population in the Basque Country, Spain. Obes Rev 8: 281-287.

27. Martínez-Vizcaíno V, Sánchez López M, Moya Martínez $P$, Solera Martinez $M$ Notario Pacheco B, et al. (2009) Trends in excess weight and thinness among Spanish schoolchildren in the period 1992-2004: the Cuenca study. Public Health Nutr 12: 1015-1018.

28. Krassas GE, Tzotzas T, Tsametis C, Konstantinidis T (2001) Prevalence and trends in overweight and obesity among children and adolescents in Thessaloniki, Greece. J Pediatr Endocrinol Metab 14 Suppl 5: 1319-1326.

29. Wang Y, Monteiro C, Popkin BM (2002) Trends of obesity and underweight in older children and adolescents in the United States, Brazil, China, and Russia. Am J Clin Nutr 75: 971-977.

30. Lissau I, Overpeck MD, Ruan WJ, Due P, Holstein BE, et al. (2004) Body mass index and overweight in adolescents in 13 European countries, Israel, and the United States. Arch Pediatr Adolesc Med 158: 27-33.
This article was originally published in a special issue, Childhood Obesity handled by Editor(s). Dr. Reza Hakkak, University of Arkansas for Medica Sciences, USA 